\title{
Anaemia among schoolchildren in Qena Governorate, Upper Egypt
}

\author{
P. Barduagni, ${ }^{1}$ A.S. Ahmed,${ }^{2}$ F. Curtale ${ }^{3}$ M. Raafat ${ }^{4}$ and E. Mansour ${ }^{5}$
}

SUMMARY A study was carried out during January/February 2001 in Deshna and Armant Districts of Qena Governorate, Upper Egypt, to establish the prevalence of anaemia among schoolchildren aged 6 to 11 years and define appropriate control interventions in the area. Haemoglobin levels were measured directly in schools using a portable spectrophotometer. The mean (SD) level of haemoglobin in 1844 schoolchildren in 37 schools was $12.79(1.15) \mathrm{g} / \mathrm{dL}$. Only $12 \%$ of children were below the WHO cut-off for anaemia for this age group $(<11.5 \mathrm{~g} / \mathrm{dL})$ and no cases of severe anaemia $(<7.0 \mathrm{~g} / \mathrm{dL})$ were detected. The low prevalence of mild to moderate anaemia indicates that mass iron supplementation is not justifiable, but routine monitoring of haemoglobin levels should be part of the public health activities in the schools.

\section{Introduction}

Anaemia is a serious public health problem in low- and middle-income countries, especially among women of childbearing age (15-49 years old) and their children [1]. It has negative effects on working capacity, intellectual performance and pregnancy [2]. Iron-deficient populations are also more susceptible to infectious diseases [3], because the immune system is adversely affected.

In Egypt, nutritional anaemia is the most common type of anaemia. It is mostly caused by iron deficiency or, less frequently, insufficient intake of folate and/or vita$\min B_{12}$. Besides insufficient dietary intake, deficiency of these essential nutrients in children may be due to factors such as reduced absorption during meals (e.g. due to tannin in tea and phytate in unleavened bread) [4] or to infection with intestinal helminths which cause blood loss (e.g. Trichuris trichiura, Schistosoma mansoni, hookworms, Fasciola spp.) or interfere with iron absorption in the intestinal tract (e.g. Giardia intestinalis, Ascaris lumbricoides) [5].

Iron supplementation is considered a valid action to control nutritional anaemia while underlying causes are identified and corrected [6].

In Qena Governorate, as elsewhere in Egypt, the prevalence of anaemia in children is considered to be a major problem [7], but population-based data, especially on children, are limited. A national survey, recently conducted on adolescents, detected an overall prevalence of anaemia of $46.6 \%$ among the age group $10-19$ years [8].

${ }^{1}$ General Directorate of Development Cooperation, Ministry of Foreign Affairs, Rome, Italy.

${ }^{2}$ Support Health Sector Reform in Egypt, Ministry of Health and Population, Qena Governorate, Egypt. ${ }^{3}$ Instituto Superiore di Sanità, Ministry of Health, Rome, Italy.

${ }^{4}$ Suport Health Sector Reform in Egypt; ${ }^{5}$ Department of Primary Health Care, Ministry of Health and Population, Cairo, Egypt. 
Although children from 6 to 11 years of age are not considered at-risk of anaemia, the present study targeted schoolchildren because a former study in Behera Governorate detected a high prevalence of anaemia in this age group [9]. Furthermore, children attending primary schools are easily accessible and the selection of this target group enhances the costeffectiveness of targeted interventions. The aim of this study was to collect populationbased data on the prevalence of anaemia among schoolchildren aged 6-11 years to define appropriate control interventions.

\section{Methods}

\section{Sample}

The field assessment was carried out during January and February 2001 in Deshna and Armant districts, which are considered typical rural districts of Qena Governorate, Upper Egypt.

The study group included children from 6 to 11 years of age attending the primary schools in the 18 villages of the 2 districts. The minimum sample size was calculated for Armant as 337 schoolchildren, with an expected frequency of $35 \%$, a worst acceptable frequency of $25 \%$ and a confidence level of $99.99 \%$ [10]. Following the same procedure, the minimum sample size for Deshna district was calculated as 682 children. Therefore, the total minimum sample size for the two districts was 1019 schoolchildren.

For the definition of the anaemia control intervention, it was relevant to relate anaemia data to the population of the 18 villages of the 2 districts, therefore the selected schools were chosen with a probability of inclusion proportionate to the village size. In total, 16 schools were selected in Armant district and 21 schools in Deshna district. In each school, 50 pupils were se- lected from classes 1 to 5 and for each class the first 10 on the register were selected. The calculated total sample size was 1850 schoolchildren from 6 to 11 years of age.

\section{Blood analysis}

Haemoglobin levels were assessed directly in the schools, using a portable haemoglobin spectrophotometer (HemoCue, Sweden). The sample was performed on capillary blood from the fingertip of each child after discharge of the first drop by painless sterile safety blood lancets. A trained laboratory technician from the region performed the test, assisted by the school doctor.

According to World Health Organization (WHO) standards [11], anaemia was defined in school-age children as a haemoglobin level $<11.5 \mathrm{~g} / \mathrm{dL}$ and severe anaemia as $<7.0 \mathrm{~g} / \mathrm{dL}$.

All children found to be anaemic were treated according to the Egyptian Ministry of Health and Population guidelines and, if other pathologies were detected, children were referred to the appropriate level of care.

\section{Analysis}

Data were analysed by Epi-Info software, version 6.04 .

\section{Results}

Out of the 1850 expected blood samples, results of haemoglobin assessments were available from 795 children of Armant district (424 male and 371 female), and from 1044 children of Deshna district (534 male and 515 female). This gave a total of 1844 schoolchildren from 6 to 11 years of age, of whom $958(52 \%)$ were boys and 886 $(48 \%)$ were girls. 
The mean level of haemoglobin in the study population was $12.79 \mathrm{~g} / \mathrm{dL}$ (standard deviation $=1.15)$. Out of the total number of examined children, 123 boys $(6.7 \%)$ and 99 girls $(5.4 \%)$, a total of 222 children $(12.0 \%)$, were below the WHO cut-off point indicative for anaemia for the age group 6-11 years old (haemoglobin $<11.5$ $\mathrm{g} / \mathrm{dL})$. No case of severe anaemia $(<7.0 \mathrm{~g} /$ dL) was detected. The prevalence of anaemia was $12.8 \%$ among boys and $11.2 \%$ among girls, but this difference was not statistically significant. In Armant district, out of 795 children, 96 (12.1\%) were anaemic and in Deshna district, out of 1044 children, 126 (12.1\%) were anaemic.

As shown in Figure 1, the prevalence of anaemia was higher among the pupils in grade $1(16.9 \%)$ and gradually decreased towards grade $5(9.5 \%)$.

Only 5 villages out of 18 reported a prevalence of anaemia higher than 20\% among this age group of children.

\section{Discussion}

The results show that, among schoolchildren from 6 to 11 years of age living in ru- ral Upper Egypt, the prevalence of anaemia is low and its severity is moderate. On the basis of the perceptions of health personnel and other studies performed on adolescents [12] in similar areas, a higher prevalence of anaemia among school-age children was expected. To interpret this result we can assume that the dietary intake in the area is currently just sufficient to satisfy the iron needs of the majority of school-age children. The higher prevalence of anaemia found among adolescents may be attributed to increased needs for iron due to rapid growth and the menarche [13]. Furthermore, a low prevalence and moderate intensity of intestinal helminth infections in the region have been reported in former studies [14] and the relationship between anaemia and infection with intestinal helminths (Trichuris, Schistosoma or Ascaris spp.) is well known [15]. The habit of consuming tea after meals has been demonstrated to affect iron absorption [16], but according to discussions with doctors and leaders of the local community, it is an uncommon practice in the research area, since the consumption of tea among rural school-age children is generally limited to

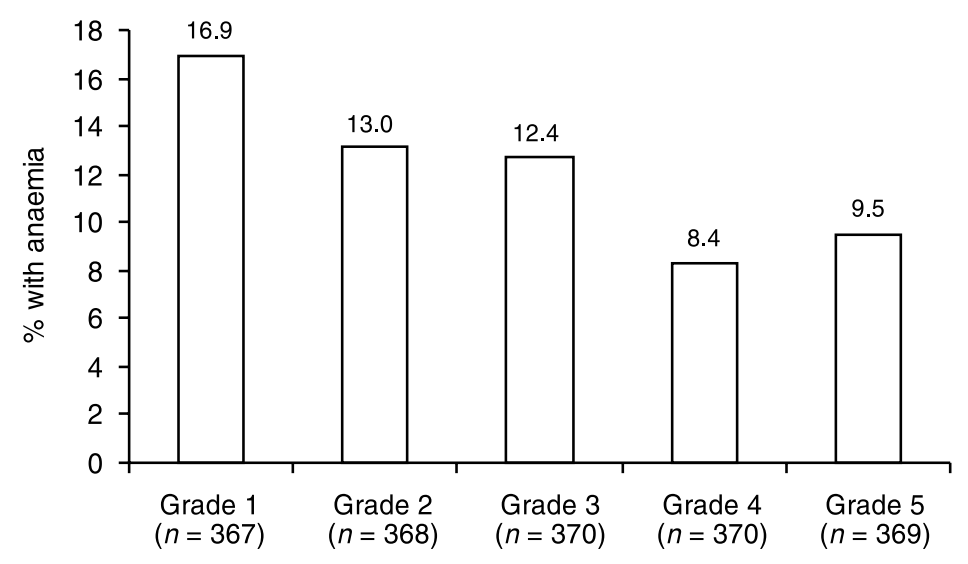

Figure 1 Percentage of schoolchildren with anaemia at each school grade ( $n=$ number of haemoglobin assessments)

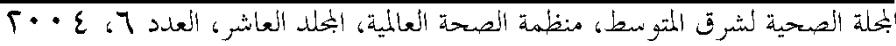


breakfast and in most cases together with milk.

Socioeconomic conditions were not investigated in this study, since only public schools are available in this area, so the great majority of children of the 2 rural districts attend the same schools, irrespective of their socioeconomic status.

In conclusion, the study showed that the problem of anaemia among school-age children in the Qena region is not severe and therefore mass iron supplementation in primary schools is not recommended. However, children in the first year of school reported the highest rates of anaemia and they should be a priority target for a control programme. In the villages where schools had anaemia rates higher than $20 \%$ of pupils, weekly iron supplementation to all school-age children should be considered. In view of the prevalence of mild to moderate anaemia in the area, how- ever, haemoglobin levels should be closely monitored and be part of the routine public health activities in primary and secondary schools.

\section{Acknowledgements}

The present study was implemented in the framework of the bilateral cooperation programme "Strengthening Rural Health Services in Behera, Qena and Dakhalia Governorates" between the Primary Health Care Department of the Ministry of Health and Population (MoHP), Egypt, and the Directorate General for Development Cooperation, Ministry of Foreign Affairs, Italy. The authors would like to thank all the district and regional MoHP personnel of Qena Governorate who actively participated to achieve the success of this fieldwork.

\section{References}

1. Meeting between the World Health Organization and the Partnership for Child Development (Geneve, 7-8 December 1993). Geneva, World Health Organization, 1993 (WHO/CDS/IPI/94.1).

2. DeMaeyer EM et al. Preventing and controlling iron deficiency anaemia through primary health care. Geneva, World Health Organization, 1989.

3. Draper A. Child development and iron deficiency. The Oxford brief. Washington, DC, International Nutritional Anemia Consultative Group, 1997.

4. Verster A, van der Pols JC. Anaemia in the Eastern Mediterranean Region. Eastern Mediterranean health journal, 1995, 1:64-79.

5. Tomkins A, Watson F. Malnutrition and infection: a review. ACC/SCN State-of-
the-Art Series. Nutrition Policy Discussion Paper No. 5. Geneva, United Nations, 1989.

6. Verster A, ed. Guidelines for the control of iron deficiency in countries of the Eastern Mediterranean, Middle East and North Africa. Alexandria, World Health Organization Regional Office for the Eastern Mediterranean, 1996 (WHOEM/NUT/177, E/G/11.96).

7. Moussa WA. Nutritional status in Egypt. Final report of the Health Examination Survey. Cairo, Ministry of Health, 1990 (Publication 38/1).

8. El-Tawila $\mathrm{S}$ et al. Transition to adulthood. A national survey of Egyptian adolescents. Cairo, Population Council, 1999.

9. Curtale $\mathrm{F}$ et al. Anaemia and intestinal parasitic infections among school age

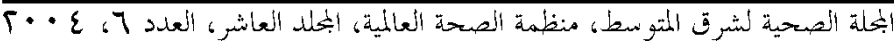


children in Behera Governorate, Egypt. Behera Survey Team. Journal of tropical pediatrics, 1998; 44:323-8.

10. Lwanga SK, Lameshow S. Sample size determination in health studies. Geneva, World Health Organization, 1991.

11. Stoltzfus RJ, Dreyfuss ML. Guidelines for the use of iron supplements to prevent and treat iron deficiency anaemia. Washington DC, International Nutritional Anaemia Consultative Group/WHO/ UNICEF, 1998.

12. El-Sahn $\mathrm{F}$ et al. Anaemia among Egyptian adolescents: prevalence and determinants. Eastern Mediterranean health journal, 2000, 6:1017-27.

13. Brabin L, Brabin BJ. The cost of successful adolescent growth and development in girls in relation to iron and vitamin $\mathrm{A}$ status. American journal of clinical nutrition, 1992, 55:955-8.

14. Curtale $\mathrm{F}$ et al. Knowledge, perception and behaviour of mothers toward intestinal helminths in Upper Egypt: implications for control. Health policy and planning, 1998, 13(4):423-42.

15. Stephenson LS. Impact of intestinal helminths on human nutrition. New York, Taylor and Francis, 1987.

16. Disler PB et al. The mechanism of the inhibition of iron absorption by tea. South Africa journal of medical science, 1976, 40:109-16.

\section{Mote from the Editor}

We would like to draw our readers' attention to the evaluation form at the end of this issue. We welcome comments from our readers, which can help us improve the EMHJ. We would appreciate it therefore if readers could kindly take the time to complete this form and return it to us. Alternatively, the form can be completed online at: http://www.emro.who.int/publications/emhj/evaluationform.asp

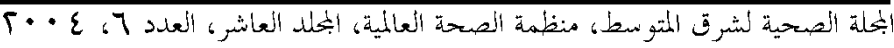

